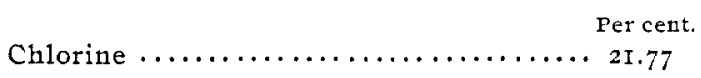

Monochlor naphthol requires 19.66 per cent.; dichlor naphthol requires 33.02 per cent. There was evidently no simple substitution of $\mathrm{Cl}$ for $\mathrm{NO}_{2}$, and it was plain that more complicated changes than those involved by substitution had taken place. The inability to obtain a product offering the assurance of purity, caused a discontinuance of the work. The expulsion of the nitro group by chlorine under these conditions, is, however, worthy of note.

\title{
THE RATE OF SOLUTION OF SOLID SUBSTANCES IN THEIR OWN SOLUTIONS.
}

By ArthuR A. Noyes aND WrLlis R. Whitsey.

Received October $\mathrm{II}, 2897$.

$A$ s far as we know, the effect of the concentration on the rate has not heretofore been investigated. This is probably due to the experimental difficulties in the way of keeping the surface of the dissolving substance constant during the solution.

The question is an important one, especially because of the light its solution would throw upon the attainment of the state of saturation, which is a matter of importance in all solubility determinations. Therefore we have investigated the phenomenon and have succeeded in experimentally establishing the law according to which the process takes place.

The experiments were carried out in the following manner: In order to keep the alteration of the surface-area of the dissolving substances as small as possible, the slightly soluble substances, benzoic acid and lead chloride, were chosen. Cylinders of these two substances, about eight $\mathrm{cm}$. long and two in diameter, were prepared upon cores of glass. In the case of benzoic acid, this was done by simply pouring the melted acid into a testtube containing a glass rod flattened a little at the lower end and protruding at the other end above the test-tube. When the whole had cooled, the cylinder of acid adhering well to the glass rod could usually be easily removed from the tube. It was found necessary in the case of lead chloride to proceed differ- 
ently, because the cylinders of it, made as above, broke upon cooling. They were finally made by dipping the glass rods into the molten salt, removing then a second or two to allow them to cool, and repeating the operation until a sufficient amount had solidified upon the rods. Both ends of the cylinders of the two substances were coated with paraffin, and the free ends of the glass rods were forced through the centers of numbered paraffined corks, each of which fitted into a wide-mouthed bottle of I $30 \mathrm{cc}$. capacity.

In conducting the experiments, exactly too cc. of distilled water were placed in each of the six bottles, and these were suspended in a thermostat kept at $25^{\circ} \mathrm{C}$. within a few thousandths of a degree. After the temperature of the bath had been attained, the corks bearing the sticks of substance were inserted in the bottles so that the cylinders were in the middle of the bottle, and covered with water, as shown in the cut. The

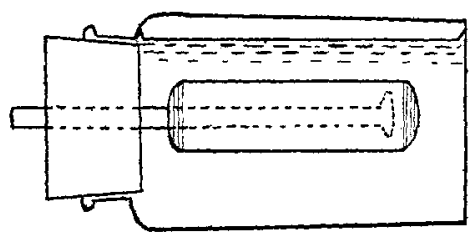

time was then noted and the bottles were rotated ${ }^{1}$ in a horizontal position in the bath exactly ten (or ten and a half) minutes, at the rate of sixty rotations per minute. The sticks were then removed from the bottles; and the solutions titrated directly, in the case of the benzoic acid, with sodium hydroxide solution, and in that of the lead chloride, with silver nitrate and potassium thiocyanate. The same sticks were then returned to the bottles, which were charged with new portions of $100 \mathrm{cc}$. of water, and were rotated as before for thirty, and finally for sixty minutes, when the resulting solutions were analyzed. In order to have as nearly as possible the same conditions in the different experiments, each series of three determinations was made with the same stick of material in the same bottle, and each series was repeated several times. During the time elapsing between separate rotations, the sticks were kept in saturated solutions of

1 For a description of the rotation apparatus, see Ztschr. phys. Chem., 9, 606. 
the respective substances, so that they could not become dry, nor altered in surface.

The law governing the rate of solution can be predicted with a considerable degree of probability; for the phenomenon may be considered as simply a process of diffusion. That is, we can imagine the sticks of solid substances surrounded by an indefinitely thin film of saturated solution, from which diffusion takes place into all portions of the solvent, this being kept homogeneous by the rotation. If this were the case, the velocity of solution, in accordance with the law of diffusion, would be proportional to the difference between the concentration of the saturated solution and that of the solution present at the moment in question. This is then the law which is first to be tested. Its mathematical expression is :

$$
\frac{d x}{d t}=C(S-x),
$$

where $S$ represents the solubility of the substance, or the concentration of its saturated solution; $x$ the concentration at the expiration of the time $t$, and $C$ a constant. Integration of the equation gives:

$$
C=\frac{\mathrm{I}}{t} \log _{\mathrm{e}} \frac{S}{S-x} .
$$

In order to obtain values for $C$ in this equation, the solubility $S$ of the substance must be known. This was determined in the usual manner ${ }^{1}$ by rotating a large excess of the finely divided substance in the bottles of water, proceding so that the condition of equilibrium was approached from both the undersaturated and supersaturated states. The results of the solubility determinations are given below. The separate values obtained are designated by $S_{1}, S_{2}, S_{3}$, and $S_{4}$, and the mean is represented by $S$. They are expressed in millimols per liter.

$\begin{array}{cccccc}\text { Substance. } & S_{1} . & S_{2} . & S_{3} . & S_{4} . & S . \\ \text { Benzoic acid....... } & 27.88 & 28.1 \text { I } & 27.96 & \mathbf{2 7 . 7 5} & \mathbf{2 7 . 9 2} \\ \text { Lead chloride..... } & 39.00 & 38.94 & 38.50 & 38.50 & 38.66\end{array}$

The results of the velocity experiments are given in the following table. The values of $x_{1}, x_{2}$, etc., are the concentrations

1 Ztschr. phys. Chem., 16, I28. 
in millimols of the solutions resulting from successive treatments, carried out as described above, of the same stick of substance. The values under $x$ are the means of these single values.

BenzoIC ACID.

Stick No. $I$.

\begin{tabular}{|c|c|c|c|c|c|c|c|c|c|}
\hline $\begin{array}{l}t . \\
\text { IO }\end{array}$ & $\begin{array}{l}x_{1} \\
6.27\end{array}$ & $\begin{array}{l}x_{2} \\
6.69\end{array}$ & $\begin{array}{l}x_{\mathrm{g}} \\
6.55\end{array}$ & $\begin{array}{c}x_{4} \\
6.77\end{array}$ & $\begin{array}{l}x_{b} . \\
6.20\end{array}$ & $\begin{array}{l}x_{8} \\
5.62\end{array}$ & $\begin{array}{c}x \\
6.35\end{array}$ & $\begin{array}{l}S-x . \\
21.57\end{array}$ & $\begin{array}{c}C . \\
\text { II } 2 . \text { I }\end{array}$ \\
\hline 30 & 14.45 & 14.47 & I5.22 & 15.27 & 14.48 & $\cdots$ & 14.78 & I3.I4 & $\log . I$ \\
\hline 60 & 21.70 & $2 \pi .44$ & $22.5^{6}$ & 21.80 & $20.5 I$ & $\ldots$ & 21.60 & 6.32 & 107.5 \\
\hline \multicolumn{10}{|c|}{ Stick No. z. } \\
\hline 0 & 6.32 & 6.40 & 6.33 & 7.64 & 6.43 & 5.16 & $6.3^{8}$ & $2 I .54$ & II 2.7 \\
\hline 30 & 15.33 & I5. I9 & $I_{5} \cdot 5^{\circ}$ & I6.39 & $\mathrm{I}_{5} . \mathrm{I} 2$ & $\ldots$ & I $5.5 \mathrm{I}$ & I $2.4 \mathrm{I}$ & II 7.4 \\
\hline & 22.I5 & 22.30 & 22.13 & 21.43 & $2 \mathrm{I} .44$ & $\cdots$ & 21.89 & 6.03 & 110.9 \\
\hline \multicolumn{10}{|c|}{ Stick No.3. } \\
\hline co & 8.84 & 9.32 & 9.07 & 9.22 & 8.15 & 7.85 & 8.74 & 19.18 & 163.0 \\
\hline & 18.15 & 20.15 & 19.73 & 17.63 & $I 6.8 \mathrm{I}$ & $\cdots$ & I8.49 & 9.43 & $157 . \mathrm{I}$ \\
\hline & 24.95 & 24.92 & 25.22 & 24.67 & 24.20 & $\cdots$ & 24.79 & 3.13 & I60.I \\
\hline \multicolumn{10}{|c|}{ Stick No. 4 . } \\
\hline & 5.47 & 5.52 & 6.49 & 6.28 & $5 \cdot 77$ & 5.72 & 5.87 & 22.05 & 102.5 \\
\hline & 14.05 & I $4 \cdot 36$ & $I 4.2 I$ & 14.97 & 13.40 & $\ldots$ & 14.20 & 13.72 & 102.8 \\
\hline & 22.I9 & $\cdots$ & I9. 47 & 19.88 & 19.90 & $\cdots$ & 20.33 & $7 \cdot 59$ & 94.3 \\
\hline
\end{tabular}

LEAD CHLORIDE.

Stick No. $r$.

\begin{tabular}{|c|c|c|c|c|c|c|c|c|}
\hline $\begin{array}{c}t \\
\mathrm{I} O \frac{1}{2}\end{array}$ & $\begin{array}{l}x_{1} . \\
\ldots\end{array}$ & $\begin{array}{c}x_{2} \\
5.96\end{array}$ & $\begin{array}{c}x_{3} . \\
6.56\end{array}$ & $\begin{array}{r}x_{4} \\
5.70\end{array}$ & $\begin{array}{c}x_{5} \\
6.35\end{array}$ & $\begin{array}{c}x \\
6.14\end{array}$ & $\begin{array}{l}S-x \\
32.52\end{array}$ & $\begin{array}{c}C . \\
7 \mathrm{I} .5\end{array}$ \\
\hline 30 & $\ldots$ & $\ldots$ & I5.9 & I5.5 & I 5.8 & I5.73 & 22.93 & 75 \\
\hline 60 & $\ldots$ & ... & 25.5 & 35.7 & 22.5 & $24.5^{8}$ & 14.08 & 72. \\
\hline
\end{tabular}

Stick No. 2 .

$\begin{array}{llllllrrr}10 \frac{1}{2} & 9.93 & 9.01 & 10.05 & 9.40 & 10.21 & 9.73 & 28.93 & 119.0 \\ 30 & 23.8 & 20.6 & 22.6 & 22.7 & 22.2 & 22.38 & 16.28 & 125.4 \\ 60 & 31.9 & 31.9 & 30.4 & 31.9 & 30.8 & 31.38 & 7.28 & 120.9\end{array}$

Stick No.3.

$\begin{array}{lllllllll}\text { IO } \frac{1}{2} & 8.17 & 7.04 & 7.25 & 7.50 & 7.20 & 7.43 & 3 \mathrm{I} .23 & 88.2\end{array}$

$\begin{array}{lllllllll}30 & 20.4 & \text { I8.8 } & \text { I8.4 } & \text { I 7.4 } & \text { I8.2 } & 18.64 & 20.02 & 95.2\end{array}$

$\begin{array}{lllllllll}60 & 26 . I & 27.1 & 28.4 & 26.8 & 26.8 & 27.02 & \text { II.64 } & 86.9\end{array}$

Stick No. 4 .

$\begin{array}{lllllllll}10 \frac{1}{2} & 6.18 & 4.84 & 4.8 \mathrm{I} & 4.17 & 4.50 & 4.90 & 33.76 & 56.0\end{array}$ $\begin{array}{lllllllll}30 & \text { I5.I } & \text { I5.4 } & \text { I3.7 } & \text { I2.0 } & \text { II.4 } & \text { I3.52 } & 25.14 & 62.3\end{array}$ $\begin{array}{lllllllll}60 & 23.1 & 23.0 & 22.6 & 21.2 & 18.0 & 21.58 & 17.08 & 59.2\end{array}$ 
It is evident from these results that the calculated constants vary usually irregularly and but little.

As this is the case with two substances of so widely different chemical nature and physical properties as benzoic acid and lead chloride, it is safe to assume that the law is a general one. It may be expressed as follows: The rate at which a solid substance dissolves in its own solution is proportional to the difference between the concentration of that solution and the concentration of the saturated solution.

Massachusetts INstitete of Technology, Boston, MAY, I897.

\title{
THE ANALYSIS OF BEARING-METAL ALLOYS, WITH A NEW VOLUMETRIC METHOD FOR DETERMINING COPPER. ${ }^{1}$
}

\author{
BY W, E. Garrigues.
}

Received October 28,1897 .

$\int U$ UDGING by the number of articles that continue to appear from year to year in chemical journals, elaborating more or less complete schemes for the analysis of these alloys, the subject is still a timely one for discussion. There is, furthermore, small likelihood that this apparent interest will $\mathrm{lag}$, in the near future at least, owing to the evident fact-and it is one that must not be lost sight of in passing judgment on the merit of such a combination of methods for separation and determination as the present paper deals with-that we are not considering a material capable of being handled like steel, where accurate methods have been found for ascertaining the quantity of almost every element present without the necessity of first removing three or four others from solution.

In the light of our present knowledge of the chemical deportment of the metals of the hydrogen sulphide and ammonium sulphide groups, all methods which even approach accuracy must of necessity be comparatively tedious. Not alone is it essential in almost every case to free a solution from interfering elements to reach the one sought, but in very many instances it is all but impossible to get the former out of the way without sustaining loss of the latter. Add to this the manipulative difficulties such as the washing of slimy precipitates that persist in I Read before the Chemical Section of the Engineers Society of Western Pennsylvania. 